\title{
Aorta Remodeling Responses to Distinct Atherogenic Stimuli: Hyperten- sion, Hypercholesterolemia and Turbulent Flow/Low Wall Shear Stress
}

\author{
Cibele M. Prado and Marcos A. Rossi* \\ Department of Pathology, Faculty of Medicine of Ribeirão Preto, University of São Paulo, S.P., Brazil
}

\begin{abstract}
This review is based on recently published data from our laboratory. We investigated the role of hypertension and laminar flow, hypercholesterolemia and laminar flow and turbulent blood flow/low wall shear stress, and turbulent blood flow/low wall shear stress associated with hypercholesterolemia on aorta remodeling of rats feeding normal diet or hypercholesterolemic diet. Our findings suggest that increased circumferential wall tension due to hypertension plays a key role in the remodeling through biomechanical effects on oxidative stress and increased TGF- $\beta$ expression; the remodeling observed in the presence of hypercholesterolemia could be initiated by oxidative stress that is involved in several processes of atherogenesis and this remodeling is more pronounced in the presence of turbulent blood flow/low wall shear stress.
\end{abstract}

\section{INTRODUCTION}

Atherosclerosis is a systemic, diffuse process with multifocal distribution involving the aorta and its conduits and by which the vascular intima becomes thickened with lipid rich gruel (atheroma) and connective tissue (sclerosis). The atherosclerotic lesions localize preferentially in particular regions of the arterial wall, like bends, branches and bifurcations $[1,2]$. Among known risk factors, hypertension and hypercholesterolemia are considered of utmost importance. Hypertension causes intimal and medial thickening and increase in connective tissue content [3]. The exact underlying mechanism of the association between hypertension and atherosclerosis is, however, not fully understood [4]. The association between cholesterol levels and atherogenesis was for the first time experimentally demonstrated in rabbits almost a century ago [5]. The twentieth century was the era of cholesterol and lipoproteins, culminating in a series of large-scale clinical trials showing conclusively that correcting hypercholesterolemia profoundly reduces morbidity and mortality from disease of the coronary arteries of the heart [6]. Recent serial clinical and intravascular ultrasound trials have demonstrated concordant beneficial effects of lipid-lowering treatment on arterial remodeling, including a reduction in adverse cardiovascular events and atherosclerotic plaque stabilization [7-9]. Taking into account the multi-focal distribution of the atherosclerotic plaques, it is a challenge to explain how equal concentrations of cholesterol bathing the endothelium or high blood pressure levels can produce local rather than global effects on arteries. Since there are numerous reproducible sites that are prone to developing atherosclerosis, a localizing element should be operating.

The high-susceptibility sites prone to development of atherosclerosis are thought to be conditioned by hemodynamic parameters, particularly associated with regions of

*Address correspondence to this author at the Department of Pathology, Faculty of Medicine of Ribeirão Preto, University of São Paulo, 14049-900 Ribeirão Preto, SP, Brazil; Tel/Fax: +55 163602 3130;

E-mail: marossi@fmrp.usp.br low wall shear stress, oscillatory flow, or turbulent flow [2, $10,11]$. Although they are not by themselves responsible for the pathogenesis of atherosclerosis, they may prime the local vascular wall in which the lesions develop. Wall shear stress and stretch are the most important hemodynamic forces involved [12-14]. Shear stress is a frictional force parallel to the wall at the surface of the endothelium. Low wall shear stress, especially when blood flow is turbulent, is said to play important role in the pathogenesis of the atherosclerotic plaque [13]. On the other hand, the stretch stimulus can be evaluated as two factors: circumferential wall tension and tensile stress. The first one is due to transmural pressure and the second one act perpendicularly to the arterial wall and results from the dilating effect of blood pressure on the vessel. High stretch stimulus also plays a key role in the progress of atherosclerosis [12-15]. Designing experiments that allow the establishment of a hydrodynamic milieu to study how hemodynamic forces interplay with risk factors appears to be a very useful strategy. This review is based on recently published data from our laboratory analyzing the role of hypertension, hypercholesterolemia and turbulent blood flow on aorta remodeling of rats feeding normal or hypercholesterolemic diet.

\section{AORTA COARCTATION MODEL AND BLOOD PRESSURE ANALYSIS}

The abdominal aorta was narrowed just below the diaphragm as described previously [16]; sham-operated animals underwent an identical surgical procedure, but aortic constriction was omitted. The constriction reduced about $80 \%$ of the aorta lumen. Animals were divided in sham-operated, operated, sham-operated+hypercholesterolemic diet (HD), and operated+HD. The aortic tube proximal (prestenotic segment) and distal (poststenotic segment) to the stenosis or corresponding segments from sham-operated animals were transversally cut into 5-6 $\mathrm{mm}$ long fragments.

This model of aortic constriction produces a hypertensive prestenotic segment associated with increased circumferential wall tension, normal tensile stress, and laminar flow/ 
normal wall shear stress and a normotensive poststenotic segment associated with turbulent flow/low wall shear stress, normal circumferential wall tension and tensile stress in animals receiving a normal diet $[15,17]$. In addition to the observation of the effects of increased blood pressure levels and blood flow disturbances in aorta wall, the effects of cholesterol alone or associated with blood flow disturbances were desirable [18]. To this objective, a diet supplemented with $4 \%$ cholesterol, $1 \%$ cholic acid and $0.5 \%$ 2-thiouracil was offered, which is known to induce hypothyroidism and hypotension in rats [19]. The infradiaphragmatic aortic constriction in these animals produces a normotensive prestenotic segment associated with normal circumferential wall tension, normal tensile stress, laminar flow/normal wall shear stress and a normotensive poststenotic segment associated with turbulent flow/low wall shear stress, normal circumferential wall tension and normal tensile stress. This way, the effects of hypertension and laminar flow, hypercholesterolemia and laminar flow, turbulent blood flow and low wall shear stress, and turbulent blood flow and low wall shear stress associated with hypercholesterolemia could be evaluated.

The mean arterial blood pressure proximal and distal to the aortic constriction, carotid and femoral pressures, respectively, were obtained in time 0 (before surgery), 24 hours, 14 and 28 days after surgery ( $\mathrm{n}=10$ per day and per group). In the operated group, the increase in carotid pressure was progressive after constriction of abdominal aorta. After $24 \mathrm{~h}$, the increase was $7.8 \%(p>0.05)$, after 14 days it was $13.2 \%$ $(p<0.01)$, and at the end of the experiment, $24.3 \%$ $(p<0.0001)$. The values of operated + HD group did not differ from sham-operated and sham-operated+HD values, although animals feeding HD have lower levels of arterial blood pressure. On the other hand, the femoral blood pressure was similar in all groups during the experiment (Fig. 1).

\section{BLOOD FLOW ANALYSIS}

We performed aorta duplex ultrasonography and color Doppler in all groups after 28 days of the surgery of aorta



coarctation ( $\mathrm{n}=10$ per group). Color Doppler showed a laminar flow in sham-operated and sham-operated $+\mathrm{HD}$ aorta and the orange-red color near the aorta wall meaning slower rate of laminar flow. Color Doppler in operated and operated + HD could demonstrate a preserved laminar flow appearing dark-orange to yellow in the prestenotic segment and a mixed of orange-red and blue in the poststenotic segment characterizing turbulent flow (Fig. 2). Blood flow rate in the prestenotic segment was not different among all groups (data not shown). On the other hand, the values in the poststenotic segment were markedly lower in operated and operated +HD in comparison with sham-operated and sham-operated+HD, respectively (Fig. 2A).

Wall shear stress (WSS) was calculated using the Poiseuille formula $\tau=4 \eta \mathrm{BFR} / \pi(\kappa \mathrm{r})^{3}$, where $\tau$ is WSS (dyne/ $\left.\mathrm{cm}^{2}\right), \eta$ is the blood viscosity (0.03 poise), BFR is blood flow rate $(\mathrm{ml} / \mathrm{min}), \pi$ is $3.14, \kappa$ is 1.25 (the shrinkage index, which is the ratio of artery diameter before and after plastic embedding) [20], and $r$ is the arterial radius (cm) [21]. There was no difference among the values in the prestenotic segments in all groups (data not shown). The values in the poststenotic were markedly lower in operated and operated +HD in comparison with sham-operated and sham-operated + HD, respectively (Fig. 2B).

\section{STRETCH EVALUATION IN VIVO}

Mean circumferential wall tension (CWT) was calculated by Laplace Law according to the following formula: $\mathrm{CWT}=\mathrm{MPB} \times(\mathrm{ID} / 2)$, where mean circumferential wall tension is expressed in dyne/cm, MPB is mean blood pressure $\left(\right.$ dynes $/ \mathrm{cm}^{2}$ ) and ID is internal diameter [14]. The ID of plastic embedded aorta was multiplied by 1.25 to correct the shrinkage after plastic embedding [20]. The mean CWT level in the prestenotic segment of operated group was markedly increased in comparison to values in sham-operated, shamoperated + HD and operated + HD groups (Fig. 2C). The values in the poststenotic segments were no different among all groups (data not shown).

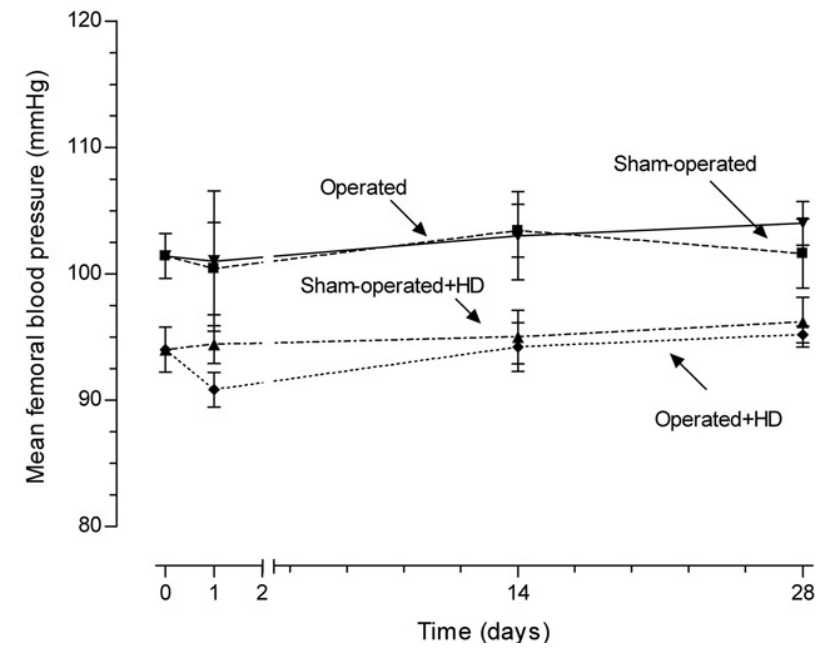

Fig. (1). Mean carotid and femoral blood pressures in operated and sham-operated groups during the 28 day period of study. In the operated group, the increase in carotid pressure was progressive after constriction of abdominal aorta. The values of operated + HD group did not differ from sham-operated and sham-operated+HD values, although animals feeding HD have lower levels of arterial blood pressure. On the other hand, the femoral blood pressure was similar in all groups during the experiment. 

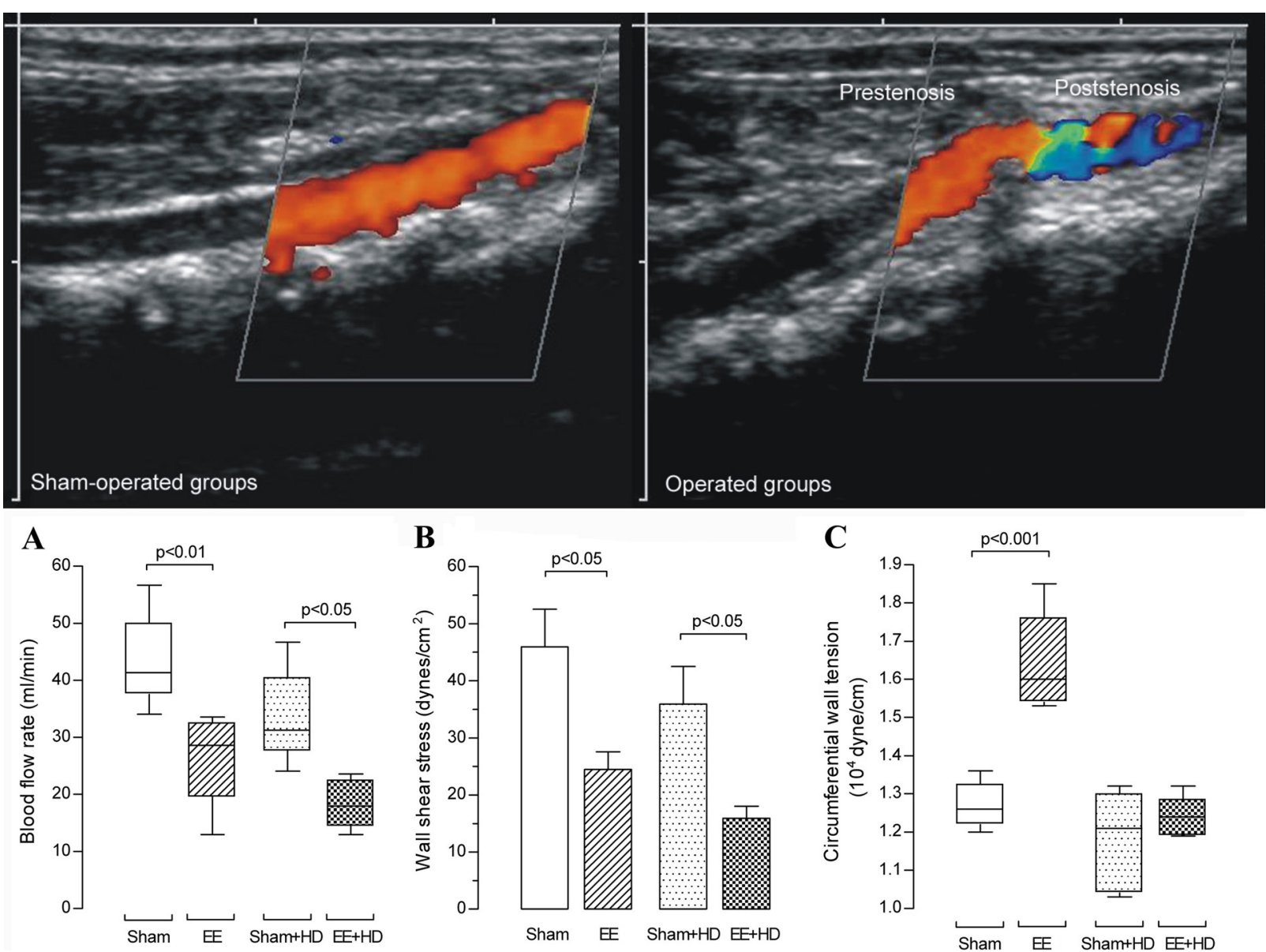

Fig. (2). Color Doppler shows a laminar flow in sham-operated groups, the dark red near the aorta wall meaning slower rate of laminar flow. Color Doppler in operated groups demonstrates a preserved laminar flow in the prestenotic segment and a mixed red, blue, green and yellow characterizing turbulent flow in the poststenotic segment. (A) Blood flow rate $(\mathrm{mL} / \mathrm{min})$. Box and whisker graph shows the batches of data in sham-operated and operated groups at Day 28 of the experiment. (B) Wall shear stress mean values (dyne/ $\left.\mathrm{cm}^{2}\right)$ in aortas from sham-operated and operated groups at Day 28 of the experiment. (C) Circumferential wall tension $\left(10^{4} \mathrm{dyne} / \mathrm{cm}\right)$ in aortas from sham-operated and operated

The medial thickening of $23 \%$ found in morphometrical analysis (data not shown) in the hypertensive prestenotic segment of operated group likely occurred in response to circumferential wall tension but not to circumferential deformation since diameter, perimeter, and luminal area of aortas in prestenotic segments were not different from those of sham-operated (data not shown). This contrasts with previous study showing that medial thickening occurred in response to circumferential deformation but not to circumferential tension in a vein-graft model in which tensions and deformation were discriminated using a band to narrow the carotid artery proximal to the vein-graft [12]. Ours results are consistent with an investigation using healthy humans demonstrating CWT positively correlated with carotid intima-media thickness [14]. It has been reported that intraluminal pressure regulates artery thickness through its effects on wall tension and blood flow regulates arterial lumen diameter through changes in wall shear stress [2, 12-14]. The increased wall thickness, mainly due to medial thickening, serves as a compensatory mechanism preventing increased arterial diameter, increased tensile stress and change of the wall shear stress. This medial thickening can be ascribed to increased expression of TGF- $\beta$ in both endothelial and smooth muscle cells in the hypertensive segments compared with discrete expression of TGF- $\beta$ in the corresponding seg- ments in sham-operated aortas (immunohistochemistry staining, data not shown). TGF- $\beta$ is a potent regulator of the cell cycle in many cells including vascular smooth muscle and endothelial cells [22]. This growth factor has been postulated to play an important, though largely undefined, role in vascular proliferative processes [23].

Tensile stress (TS) was computed as TS=CWT/IMT, where tensile stress is expressed in dyne $/ \mathrm{cm}^{2}$, CWT is circumferential wall tension $($ dyne/cm) and IMT is intimamedia thickness $(\mathrm{cm})$ [14]. The mean TS values were not different in both prestenotic and poststenotic segments among all groups, sham-operated, operated, sham-operated + HD and operated+HD (data not shown).

\section{MORPHOLOGICAL STUDY}

After 28 days of surgery, the aortas were prepared for high resolution light microscopy and morphometric analysis $(\mathrm{n}=10$ per group), immunohistochemistry ( $\mathrm{n}=10$ per group) and transmission electron microscopy ( $\mathrm{n}=5$ per group).

\section{High Resolution Light Microscopy}

The gross examination revealed that both prestenotic and poststenotic segments were similar in all groups. The use of plastic embedding allowed $2 \mu \mathrm{m}$ thick sections with good resolution of structural details. 
Aortas from operated group demonstrated in the hypertensive prestenotic segment changes characterized by intimal thickening with enlarged endothelial cells and diffusely distributed neointimal plaques composed of smooth muscle cells and occasional mononuclear cells with collagen and elastic fibers surrounding them and medial thickening (Fig. 3C), contrasting with the delicate structure of the intima in the sham-operated group (Fig. 3A). Aortas from shamoperated + HD (Fig. 3B) and operated+HD (Fig. 3D) revealed diffusely distributed foci of small flat lesions corresponding microscopically to fatty streaks characterized by intimal foam cells accumulation, contrasting with the delicate structure of the intima in the sham-operated group. When the percentile frequency distribution of intima thickness in the prestenotic segment of all groups was plotted, it can be clearly seen the shift to the right of the values of operated group and in comparison with the values in corresponding segment in sham-operated animals. The diffuse intimal thickening and diffusely neointimal plaques observed in the operated group and the small flat lesions observed in shamoperated + HD and operated+HD can be evidenced (Fig. 3G).

In the poststenotic segment, aortas from operated group showed intima delicate quite similar to the intima in the sham-operated, except for focally distributed neointimal plaques similar to those observed in the prestenotic segment but many of them larger in size (Fig. 3E). In operated+HD aortas, focally distributed incipient atherosclerotic lesions characterized by raised focal lesions within the intima composed of smooth muscle cells, mononuclear cells and extracellular matrix were seen in this segment (Fig. 3F). The percentile frequency distribution of intimal thickness in the poststenotic segment of sham-operated $+\mathrm{HD}$, operated group and operated $+\mathrm{HD}$ was quite similar to that observed in corresponding areas of sham-operated group, except for the clear demonstrations of the occurrence of marked intimal thickening in the operated group and operated+HD (Fig. 3H).

\section{Transmission Electron Microscopy}

The transmission electron microscopy of sham-operated aortas did not differ from that reported in the literature $[15,17,24]$.

In the hypertensive prestenotic segment from operated group, the intima appeared diffusely expanded mainly due to enlarged endothelial cells showing irregular nuclear and cytoplasmic contours resting on a basement membrane-like material and delicate fibrocollagenous support tissue. Focally distributed discrete neointimal plaques could be also detected. They were composed of clusters of smooth muscle cells, randomly arranged, surrounded by basement membrane-like material, collagen and young elastic fibers (Fig. 4A). Migration of smooth muscle cells from the media into the intima through the fenestras could also be seen. The media remained intact, the smooth muscle cells appearing unaltered, retaining their orientation to the vessel. In the poststenotic segment the intima appeared comparable to that of corresponding segment of sham-operated, except for focally distributed neointimal plaques, larger than those observed in the prestenotic segments. The foci were similar to those observed in the prestenotic segment, but of larger size. No changes could be observed in the media (Fig. 4B).



C

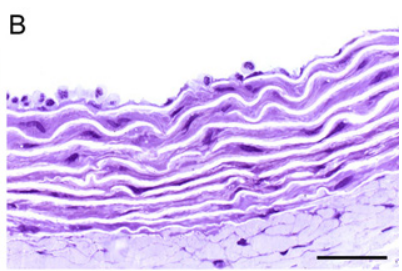

D

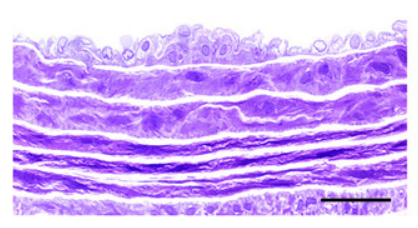

E

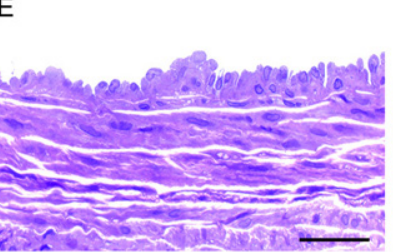

G
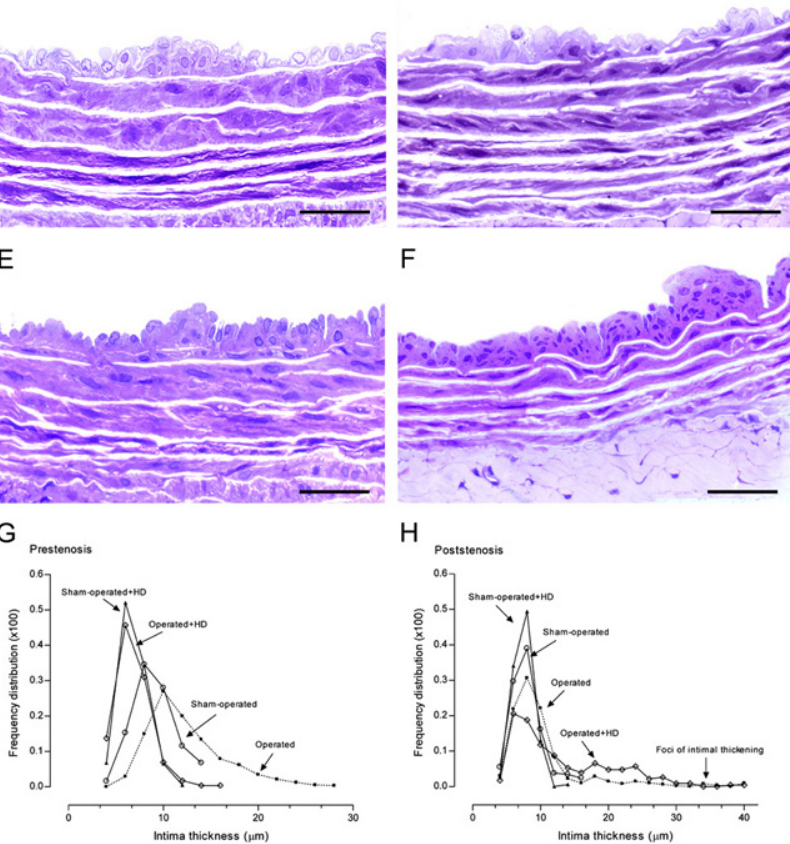

$\mathrm{F}$

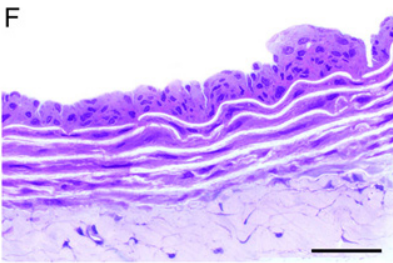

$\mathrm{H}$

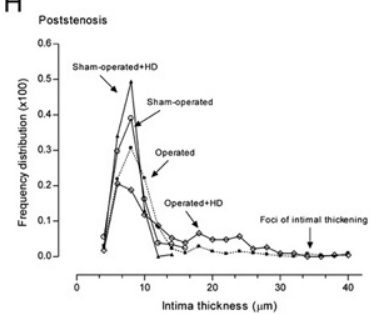

Fig. (3). High resolution light microscopy. Representative views of the aortas from sham-operated (A), prestenosis (C), poststenosis (E), sham-operated+HD (B), prestenosis +HD (D) and poststenosis + HD (F). Panel C. Intimal thickening with enlarged endothelial cells and diffusely distributed neointimal plaques composed of smooth muscle cells and occasional mononuclear cells with collagen and elastic fibers surrounding them and medial thickening can be seen, contrasting with the delicate structure of the intima in the sham-operated group (A). Panel E. Intima appeared delicate quite similar to the intima in the sham-operated, except for focally distributed neointimal plaques similar to those observed in the prestenotic segment but many of them larger in size. Aortas from sham-operated + HD (Panel B) and operated + HD (Panel D) revealed diffusely distributed foci of small flat lesions corresponding microscopically to fatty streaks characterized by intimal foam cells accumulation, contrasting with the delicate structure of the intima in the sham-operated group. Panel F. Focally distributed incipient atherosclerotic lesions characterized by raised focal lesions within the intima composed of smooth muscle cells, mononuclear cells and extracellular matrix were seen in this segment. When the percentile frequency distribution of intima thickness in the prestenotic segment of all groups was plotted, it can be clearly seen the shift to the right of the values of operated group and in comparison with the values in corresponding segment in sham-operated animals (G). The percentile frequency distribution of intimal thickness in the poststenotic segment of sham-operated $+\mathrm{HD}$, operated group and operated $+\mathrm{HD}$ was quite similar to that observed in corresponding areas of sham-operated group, except for the clear demonstrations of the occurrence of marked intimal thickening in the operated group and operated+HD $(\mathbf{H})$. Scale bars, $40 \mu \mathrm{m}$. 
The aortas from sham-operated $+\mathrm{HD}$ and operated $+\mathrm{HD}$ appeared no different from that observed in sham-operated group, except for the focal lesions described above. The small flat lesions observed in sham-operated+HD and prestenotic segment from operated+HD (Fig. 4C), corresponding to fatty streaks at the high resolution light microscopic study, were composed of mononuclear and smooth muscle cells with vacuolated cytoplasm surrounded by collagen matrix localized in the subendothelial space. In the poststenotic segment, the incipient atherosclerotic lesions at the high resolution light microscopic study were composed by vacuolated mononuclear cells and great number of smooth muscle cells, many of them vacuolated surrounded by collagen matrix (Fig. 4D).
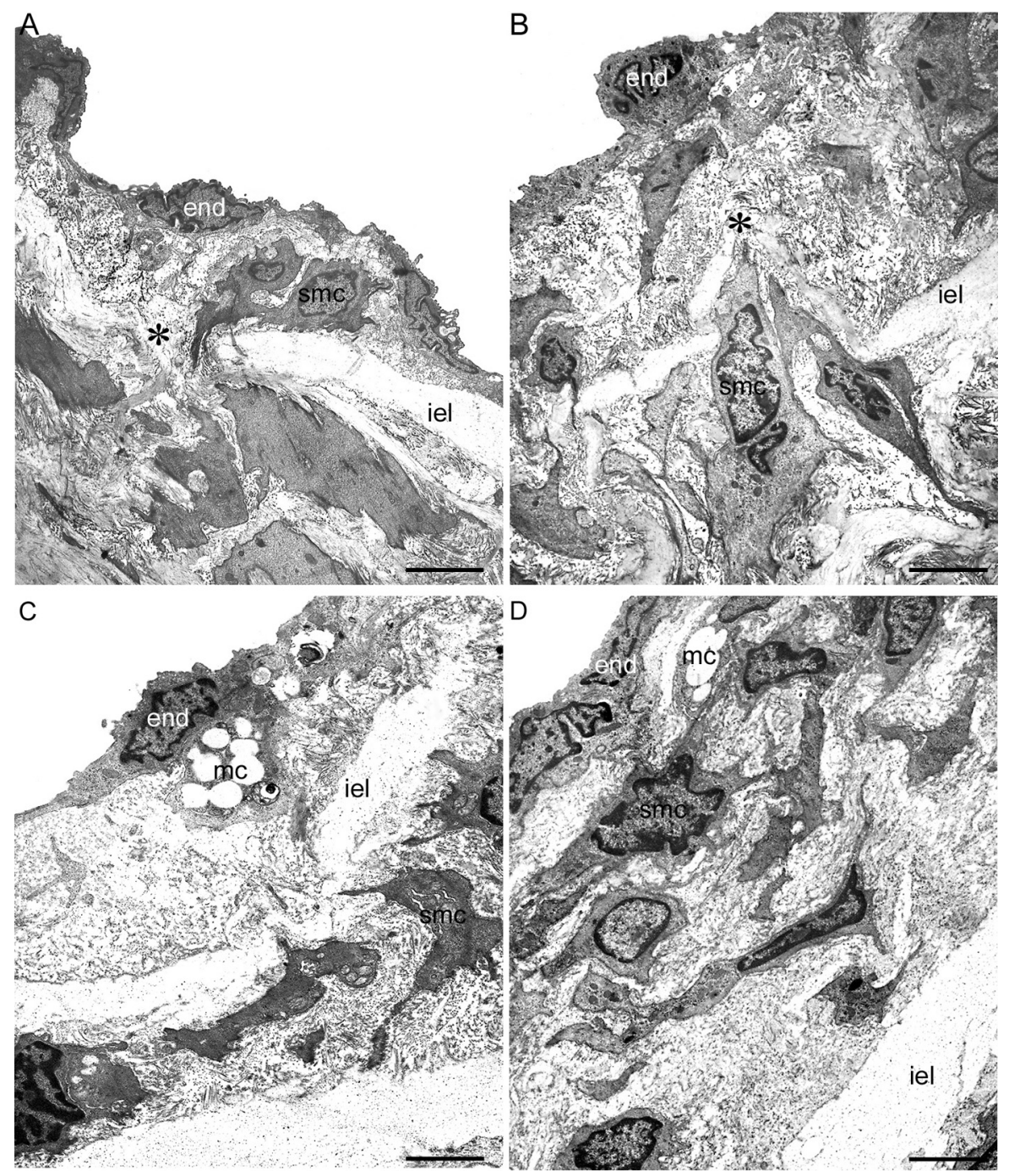

Fig. (4). Transmission electron microscopy. Representative aspects of the prestenotic (A), poststenotic (B), sham-operated + HD and prestenotic + HD (C) and poststenotic + HD (D) segments. Panel A. The intima is thickened. The endothelial cells are heterogeneous, most of them with convoluted nuclei and cytoplasmic contours. Focal accumulation of smooth muscle cells could be seen in the expanded intimal layer. Migration of smooth muscle cells from the media into the intima $\left(^{*}\right)$ through the fenestras of the internal elastic lamina can be also seen. Panel B. Marked intimal thickening composed of great number of smooth muscle cells surrounded by basement membrane-like material and collagen and elastic fibers can be seen. Migration of smooth muscle cells from the media into the intima (*) is shown. Panel C. Representative view of the small flat lesions corresponding to fatty streaks characterized by a few vacuolated mononuclear and smooth muscle cells accumulation. Panel D. Representative view of the poststenotic raised incipient atherosclerotic lesions composed of mononuclear and smooth muscle cells, many of them vacuolated, surrounded by extracellular matrix. End, endothelial cell; iel, internal elastic lamina; smc, smooth muscle cell; mc, mononuclear cell; *, migration of smooth muscle cell from the media to the intima. Scales bars, $2 \mu \mathrm{m}(\mathbf{A})$ and $3 \mu \mathrm{m}(\mathbf{B}, \mathbf{C}$, D). 
[26], whereas eNOS is a protective enzyme [27]. The increased presence of NT in endothelial cells and, mainly, smooth muscle cells, as compared with the absence or discrete expression of NT in sham-operated indicates an increased production of $\mathrm{NO}$ and superoxide that interact to produce peroxynitrite, a powerful oxidant causing damage to multiple cell components including proteins [28]. The significant accumulation of $\mathrm{NT}$, which is the footprint of $\mathrm{NO}$ oxidation/inactivation by reactive oxygen species [29], supports the supposition of endothelial dysfunction in the face of marked upregulation of eNOS and iNOS in this model, consistent with avid NO inactivation by oxidative stress in the affected vascular bed. This finding agrees with previous study showing marked increase in NT expression in the aortic segment proximal to constriction above the renal arteries [25]. An increased expression of eNOS in endothelial cells was detected in sham-operated+HD, prestenotic and poststenotic segment from operated+HD as compared with sham-operated group (data not shown). In addition, an increased expression of NT in endothelial cells and smooth muscle cells was detected in sham-operated+HD (Fig. 5D), prestenotic (Fig. 5E) and more markedly in the poststenotic segment (Fig. 5F) from operated + HD as compared with sham-operated group. It has been demonstrated that in the presence of hypercholesterolemia, eNOS generates superoxide and the endothelium acts as a source of reactive oxygen species contributing to the early atherosclerotic process [3033]. Hypercholesterolemia has been demonstrated to strikingly increase the expression of NT in endothelium, smooth muscle layers and adventitia of the aorta in rabbits [34]. The even more pronounced expression on NT in the poststenotic segments is very likely due to an additional factor, hemodynamic alterations. This assumption is supported by recent study on human coronary arteries showing that NT is present in arterial regions exposed to oscillatory shear stress (curvatures and bifurcations), but not in arterial regions exposed to pulsatile shear stress (straight segments) [35]. The accumulation of NT supports the supposition of endothelial cell dysfunction elicited by hypercholesterolemia. Although NT is considered an emergent inflammatory marker for atherosclerosis [36], the mechanism by which peroxynitrite formation contributes to atherogenesis remains uncertain.
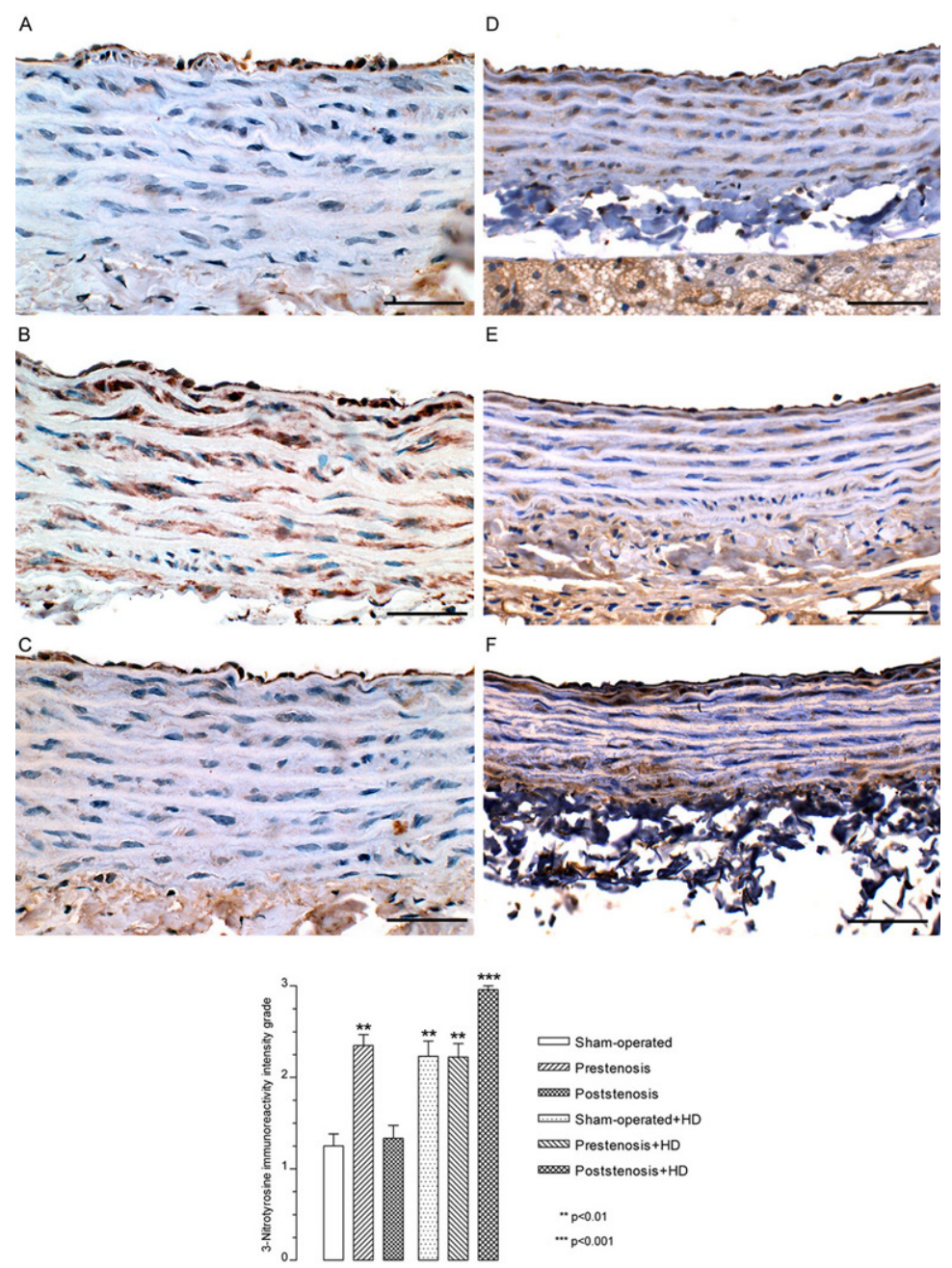

Fig. (5). Immunohistochemistry. Representative views of the aortas from sham-operated rats (A), prestenotic (B) and poststenotic (C) segments from operated rats and sham-operated + HD $(\mathbf{D})$, prestenotic $(\mathbf{E})$ and poststenotic $(\mathrm{F})$ segments from operated + HD. The graph represents the quali-quantitative evaluation of the 3-nitrotyrosine immunoreactivity grade. The analysis revealed an increased expression of 3nitrotyrosine in endothelial cells and smooth muscle cells in the prestenotic segment from operated group, sham-operated $+\mathrm{HD}$, prestenosis+HD and poststenosis+HD as compared to sham-operated group. Scale bars, $50 \mu \mathrm{m}$. 


\section{CONCLUSION}

The aortas demonstrated distinct adaptive remodeling responses to different atherogenic stimuli: hypertension, hypercholesterolemia, turbulent blood flow/low wall shear stress and turbulent blood flow/low wall shear stress+hypercholesterolemia. The first is remodeling in the hypertensive prestenotic segment with increased circumferential wall tension associated with normal tensile stress and, laminar flow/normal wall shear stress characterized by enlarged heterogeneous endothelial cells, elongated in the direction of the blood flow, diffusely distributed neointimal plaques, appearing as discrete bulging toward the vascular lumen, and medial thickening. The second is remodeling in the normotensive prestenotic segment in the presence of hypercholesterolemia and oxidative stress with laminar flow, normal circumferential wall tension and tensile stress characterized by diffusely distributed foci of small flat lesions corresponding microscopically to fatty streaks. The third is remodeling in the normotensive poststenotic segment with turbulent blood flow/low wall shear stress and normal circumferential wall tension and tensile stress characterized by groups of endothelial cells with phenotypic alterations and focally distributed neointimal plaques, similar but many of them larger than those found in the prestenotic segments of operated group. The fourth is remodeling in the normotensive poststenotic segment in the presence of hypercholesterolemia and oxidative stress with turbulent blood flow/low wall shear stress and normal circumferential wall tension and tensile stress characterized by focally distributed incipient atherosclerotic lesions composed of smooth muscle cells, mononuclear cells and extracellular matrix. Our findings suggest that increased circumferential wall tension due to hypertension play a key role in the remodeling of the prestenotic segment of operated animals through biomechanical effects on oxidative stress and increased TGF- $\beta$ expression. The remodeling observed in the presence of hypercholesterolemia could be initiated by oxidative stress that is involved in several processes of atherogenesis and this remodeling is more pronounced in the presence of turbulent blood flow/low wall shear stress. Further studies are needed to determine how the mechanical forces of turbulent flow/ low shear stress are detected and transduced into chemical sign (s) by the cells of the artery walls and then converted into pathophysiologic relevant phenotypic changes.

\section{ACKNOWLEDGEMENTS}

Supported by grants from the Fundação de Amparo à Pesquisa do Estado de São Paulo (FAPESP-01/09879-8; 06/52882-3; 06/59618-0). The authors thank Lígia B.Santoro, Maria E. Riul and Mônica A. Abreu for excellent technical assistance.

\section{REFERENCES}

[1] Ross R. Atherosclerosis-an inflammatory disease. N Engl J Med 1999; 340: 115-26.

[2] VanderLaan PA, Reardon CA, Getz GS. Site specificity of atherosclerosis: site-selective responses to atherosclerotic modulators. Arterioscler Thromb Vasc Biol 2004; 24: 12-22.

[3] Touyz RM. Molecular and cellular mechanisms regulating vascular function and structure-implications in the pathogenesis of hypertension. Can J Cardiol 2000; 16: 1137-46.

[4] Li JJ Chen JL. Inflammation may be a bridge connecting hypertension and atherosclerosis. Med Hypotheses 2005; 64: 925-29.
Anitschkow N, Chalatow S. Über experimentelle cholesterinsteatose und ihre bedeutung für die entstehung einiger pathologischer prozesse. Zentralbl Allg Pathol 1913; 24: 1-9.

[6] Steinberg D. Atherogenesis in perspective: hypercholesterolemia and inflammation as partners in crime. Nat Med 2002; 8: 1211-7.

[7] Rodriguez-Granillo GA, de Winter S, Bruining N, Ligthart JM, García-García HM, Valgimigli $M$, de Feyter PJ; EUROPA/PERSPECTIVE Investigators. Effect of perindopril on coronary remodelling: insights from a multicentre, randomized study. Eur Heart J 2007; 28: 2326-31.

[8] Schoenhagen P, Tuzcu EM, Apperson-Hansen C, et al. Determinants of arterial wall remodeling during lipid-lowering therapy: serial intravascular ultrasound observations from the Reversal of Atherosclerosis with Aggressive Lipid Lowering Therapy (REVERSAL) trial. Circulation 2006; 113: 2826-34.

[9] Tardif JC, Grégoire J, L'Allier PL, et al. Effect of atherosclerotic regression on total luminal size of coronary arteries as determined by intravascular ultrasound. Am J Cardiol 2006; 98: 23-7.

[10] Dobrin PB. Mechanical factors associated with the development of intimal and medial thickening in vein grafts subjected to arterial pressure. A model of arteries exposed to hypertension. Hypertension 1995; 26: 38-43.

[11] Lehoux S, Tedgui A. Signal transduction of mechanical stresses in the vascular wall. Hypertension 1998; 32: 338-345.

[12] Carallo C, Irace C, Pujia A, et al. Evaluation of common carotid hemodynamic forces. Relations with wall thickening. Hypertension 1999; 34: 217-21.

[13] Cunningham KS, Gotlieb AI. The role of shear stress in the pathogenesis of atherosclerosis. Lab Invest 2005; 85: 9-23.

[14] Chien S, Li S, Shyy YJ. Effects of mechanical forces on signal transduction and gene expression in endothelial cells. Hypertension 1998; 31: 162-9.

[15] Prado CM, Rossi MA. Circumferential wall tension due to hypertension plays a pivotal role in aorta remodeling. Int J Exp Pathol 2006; 87: 425-36.

[16] Rossi MA, Peres LC. Effect of captopril on the prevention and regression of myocardial cell hypertrophy and interstitial fibrosis in pressure overload cardiac hypertrophy. Am Heart J 1992; 124: 7009.

[17] Prado CM, Ramos SG, Alves-Filho JC, Elias J Jr, Cunha FQ, Rossi MA. Turbulent flow/low wall shear stress and stretch differentially affect aorta remodeling in rats. J Hypertens 2006; 24: 503-15.

[18] Prado CM, Ramos SG, Elias J Jr, Rossi MA. Turbulent blood flow plays an essential localizing role in the development of atherosclerotic lesions in experimentally induced hypercholesterolaemia in rats. Int J Exp Pathol 2008; 89: 72-80.

[19] Delia AJ, Thompson EB. A time-course study of hypothyroidisminduced hypotension: its relation to food deprivation. Arch Int Pharmacodyn Ther 1988; 296: 210-23.

[20] Zarins CK, Zatina MA, Glagov S. Correlation of postmortem angiography with pathologic anatomy: quantitation of atherosclerotic lesions. In Bond MG, Ed. Clinical Diagnosis of Atherosclerosis: Quantitative Methods of Evaluation. New York, NK: SpringerVerlag, pp 283-306, 1986.

[21] Song RH, Kocharyan HK, Fortunato JE, Glagov S, Bassiouny HS. Increased flow and shear stress enhance in vivo transforming growth factor-beta 1 after experimental arterial injury. Arterioscler Thromb Vasc Biol 2000; 20: 923-30.

[22] Massagué J. TGF-beta signal transduction. Annu Rev Biochem 1998; 67: 753-91.

[23] Topper JN. TGF-beta in the cardiovascular system: molecular mechanisms of a context-specific growth factor. Trends Cardiovasc Med 2000; 10: 132-7.

[24] Rossi MA. Colombini-Netto M. Chronic inhibition of NO synthesis per se promotes structural remodeling of the rat aorta. J Hypertens 2001; 19: 1567-79.

[25] Barton CH, Ni Z, Vaziri ND. Effect of severe aortic banding above the renal arteries on nitric oxide synthase isotype expression. Kidney Int 2001; 59: 654-61.

[26] Hernandez-Pando R, Schon T, Orozco EH, Serafin J, EstradaGarcia I. Expression of inducible nitric oxide synthase and nitrotyrosine during the evolution of experimental pulmonary tuberculosis. Exp Toxicol Pathol 2001; 53: 257-65.

[27] Heeringa P , Steenbergen E, van Goor H. A protective role for endothelial nitric oxide synthase in glomerulonephritis. Kidney Int 2002; 61: 822-25. 
[28] Nucci C, Morrone L, Rombola L, Nistico R, Piccirilli S, Cerulli L. Multifaceted roles of nitric oxide in the lateral geniculate nucleus: from visual signal transduction to neuronal apoptosis. Toxicol Lett 2003; 139: 163-73.

[29] Reiter CD, Teng RJ, Beckman JS. Superoxide reacts with nitric oxide to nitrate tyrosine at physiological $\mathrm{pH}$ via peroxynitrite. $\mathrm{J}$ Biol Chem 2000; 275: 32460-66.

[30] Collin B, Busseuil D, Zeller M, Perrin C, Barthez O, Duvillard L, Vergely C, Bardou M, Dumas M, Cottin Y, Rochette L. Increased superoxide anion production is associated with early atherosclerosis and cardiovascular dysfunctions in a rabbit model. Mol Cell Biochem 2007; 294: 225-35.

[31] Harrison D, Griendling KK, Landmesser U, Hornig B, Drexler H. Role of oxidative stress in atherosclerosis. Am J Cardiol 2003; 91: 7A-11A.

[32] Madamanchi NR, Vendrov A, Runge MS. Oxidative stress and vascular disease. Arterioscler Thromb Vasc Biol 2005; 25: 29-38.
[33] Miller FJ Jr, Gutterman DD, Rios CD, Heistad DD, Davidson BL. Superoxide production in vascular smooth muscle contributes to oxidative stress and impaired relaxation in atherosclerosis. Circ Res 1998; 82: 1298-305.

[34] Adachi T, Matsui R, Xu S, et al. Antioxidant improves smooth muscle sarco/endoplasmic reticulum $\mathrm{Ca}(2+)$-ATPase function and lowers tyrosine nitration in hypercholesterolemia and improves nitric oxide-induced relaxation. Circ Res 2002; 90: 1114-21.

[35] Hsiai TK, Hwang J, Barr ML, et al. Hemodynamics influences vascular peroxynitrite formation: Implication for low-density lipoprotein apo-B-100 nitration. Free Radic Biol Med 2007; 42: 51929.

[36] Shishehbor MH, Aviles RJ, Brennan ML, et al. Association of nitrotyrosine levels with cardiovascular disease and modulation by statin therapy. JAMA 2003; 289: 1675-80.

Received: May 12, 2008

Revised: May 28, 2008

Accepted: June 02, 2008

CC Prado and Rossi; Licensee Bentham Open.

This is an open access article distributed under the terms of the Creative Commons Attribution License (http://creativecommons.org/licenses/by/2.5/), which permits unrestrictive use, distribution, and reproduction in any medium, provided the original work is properly cited. 